\title{
Radar de penetração no solo aplicado à caracterização de estruturas tectônicas miocênicas e quaternárias no leste da ilha do Marajó (PA)
}

\author{
Ground penetrating radar applied for the characterization of Miocene \\ and Quaternary tectonic structures in Eastern Marajó Island (PA)
}

\author{
Lena Simone Barata Souza ${ }^{1}$, Dilce de Fátima Rossetti²*, Renato Luiz Prado ${ }^{3}$
}

RESUMO: Existem várias inferências sobre reativaçôes neotectônicas na ilha do Marajó, porém faltam estudos para demonstrar a presença inequívoca de estruturas que comprovem esses eventos. O objetivo deste trabalho é registrar estruturas tectônicas em subsuperfície rasa na porção oriental da ilha por meio do método geofísico eletromagnético de radar de penetração no solo (GPR). A análise de seçóes de radar resultou no reconhecimento de nove categorias de reflexôes, designadas: caótica, divergente, paralela a subparalela, ondulante, hiperbólica, em canal, em mound, sem reflexōes e superfície estratigráfica. Os últimos refletores são de frequência e amplitude altas, sendo correlacionáveis por toda a área de estudo, o que levou à sua utilização como marco estratigráfico entre duas unidades de radar. A combinaçáo de dados de radar com informaçôes geológicas permitiu concluir que a unidade inferior corresponde aos depósitos miocênicos da Formação Barreiras e a unidade superior aos sedimentos pós-barreiras, de idade pleistocênica tardia e holocênica. A superfície estratigráfica reflete a discordância do topo da Formaçáo Barreiras, sendo salientada nas seçôes de radar por concreçôes ferruginosas relacionadas a paleossolo laterítico de extensão regional. A análise das seçóes de radar mostrou que os estratos da Formação Barreiras estão fortemente deslocados por falhas verticais a subverticais, tendo-se reconhecido falhas normais e estruturas "em flor", sugestivas de transcorrência. Embora em menor grau, as falhas se prolongam para cima, afetando também os sedimentos pós-barreiras. O brusco desaparecimento de refletores relacionados à discordância do topo da Formaçáo Barreiras para oeste e norte da área de estudo, onde esta unidade é substituída por estratos quaternários, levou a concluir que, muito provavelmente, estas localidades sofreram subsidência, tornando-se sítios de sedimentação renovada no Quaternário. Além de falhas,

\begin{abstract}
There are several inferences about the occurrence of neotectonic reactivations in the Marajó Island, but studies aiming to demonstrate the unambiguous presence of tectonic structures are still lacking. The goal of this work is to record these structures in the shallow subsurface in the Eastern portion of this island applying an electromagnetic geophysical method using ground penetrating radar (GPR). Analysis of radar sections led to the recognition of nine reflection categories, designated as: chaotic, divergent, parallel to subparallel, undulating, hyperbolic, channel, mound, lack of reflection, and stratigraphic surface. The latter reflectors are of high frequency and amplitude, and are correlated along the entire study area, which led to its usage as a stratigraphic marker between two radar units. The combination of radar data with geological information allowed us to conclude that the lower unit corresponds to Miocene deposits of the Barreiras Formation and the upper unit corresponds to the post-barreiras sediments of Late Pleistocene-Holocene age. The stratigraphic surface reflects an unconformity at the top of the Barreiras Formation, which is highlighted in the radar sections by ferruginous concretions associated with a lateritic paleosol of regional extension. Analysis of radar sections showed that the strata from the Barreiras Formation are strongly displaced by vertical to subvertical faults, including normal faults and "flower" structures, the latter related to transcurrent deformation. These structures continue upward, affecting the post-barreiras sediments, though at a lower degree. The reflectors related to the unconformity at the top of the Barreiras Formation disappear rapidly to the west and north of the study area. The replacement of this unconformity by Quaternary strata led to the conclusion that those localities experienced subsidence. The subsiding areas became sites for renewed sedimentation during the Quaternary. In addition to faults,
\end{abstract}

\footnotetext{
IInstituto de Ciências Exatas e da Terra, Departamento de Geologia Geral, Universidade Federal do Mato Grosso - UFMT, Cuiaba (MT), Brasil. E-mail:lenabarata@yahoo.com.br

2Divisão de Sensoriamento Remoto, Instituto Nacional de Pesquisas Espaciais, São José dos Campos (SP), Brasil. E-mail: rossetti@dsr.inpe.br ${ }^{3}$ Instituto de Astronomia, Geofísica e Ciências Atmosféricas, Universidade São Paulo - USP, São Paulo (SP), Brasil. E-mail: renato@iag.usp.br *Autor correspondente

Manuscrito ID 30077. Recebido em: 23/01/2014. Aprovado em: 23/01/2014
} 
a base da Formação Barreiras contém amplas reflexôes ondulantes que foram atribuídas a dobras sinclinais e anticlinais. A ocorrência dessas feiçôes somente na base da Formação Barreiras permite formular a hipótese de deformação por compressão ainda durante a sedimentação dessa unidade, ou seja, no Mioceno. A ocorrência associada de falhas e dobras nos estratos miocênicos e de falhas nos sedimentos quaternários pode ser reflexo de reativaçóes de falhas transcorrentes. Estas estariam ligadas aos últimos estágios de desenvolvimento dos sistemas riftes ao longo da margem passiva equatorial brasileira.

PALAVRAS-CHAVE: neotectônica; método geofísico de radar; evolução tectono-sedimentar; norte do Brasil. the base of the Barreiras Formation contains widely undulatory reflectors, which were related to synclines and anticlines. The occurrence of these features only at the base of the Barreiras Formation allows to formulate the hypothesis that deformation by compression has occurred still during the sedimentation of this unit, i.e., in the Miocene. The association of faults and folds in the Miocene strata, as well as of faults in the Quaternary sediments, probably reflects reactivations of transcurrent faults linked to the latest evolutionary stages of the rift systems developed along of the Brazilian Equatorial passive margin.

KEYWORDS: neotectonics; radar geophysic method; tectono-sedimentary evolution; Northern Brazil.

\section{INTRODUÇÃO}

Um número crescente de publicaçôes tem demonstrado a importância do controle estrutural no estabelecimento da rede de drenagem da ilha do Marajó, bem como da evoluçáo de seu registro sedimentar durante o Pleistoceno Tardio-Holoceno (Bemerguy 1981, Costa et al. 1996, 2002, Rossetti \& Valeriano 2007, Rossetti et al. 2008a,b; Mantelli \& Rossetti 2009, Miranda et al. 2009, Rossetti 2010). Lineamentos morfoestruturais e correlaçóes estratigráficas baseadas em dados de testemunhos de sondagem têm sugerido falhas nessa regiáo, porém, inexistem estudos demonstrando sua presença de forma definitiva e inequívoca. Dada a carência de afloramentos naturais decorrentes da baixa topografia, este tipo de estudo requer o emprego de técnicas de investigação indireta por métodos geofísicos. Pesquisas geofísicas prévias na ilha consistem, principalmente, em levantamentos eletrorresistivos (e.g. sondagem elétrica vertical - SEV) (e.g., Cavalcanti 1979, Kobayashi 1979, Gonzáles 1984). Embora tendo objetivado a prospecção de água subterrânea, os resultados advindos desses estudos registram locais na ilha do Marajó onde a sedimentação quaternária é bastante expressiva, atingindo profundidades superiores a $100 \mathrm{~m}$, sugerindo áreas subsidentes proporcionadas, provavelmente, por falhas.

O presente trabalho documenta resultados de levantamento geofísico com radar de penetração no solo (GPR) na porção leste da ilha do Marajó com o objetivo de investigar estruturas tectônicas. Um grande número de publicaçôes destaca a aplicabilidade do GPR na caracterização faciológica e no mapeamento estratigráfico de sucessões sedimentares (e.g., Jol \& Smith 1991, Dominic et al. 1995, Ellefsen 1999, Dagallier et al. 2000, Lee et al. 2007), bem como no estudo de estruturas tectônicas em diferentes contextos geológicos (e.g., Basson et al. 2002, Rashed et al. 2003, Rashed \& Nakagawa 2004, Patidar et al. 2008, Chow et al. 2011, Chowksey et al. 2011, Christie 2009, Reicherter \& Reis, 2011).
No Brasil, existem vários exemplos de aplicaçóes de GPR com objetivos hidrogeológicos e sedimentológico-estratigráficos (Porsani 1999, Dourado et al. 2001, Borges \& Porsani 2002, Pereira et al. 2003, Ceia et al. 2004, Castro et al. 2005). Estruturas tectônicas neógenas também têm sido caracterizadas com o uso dessa técnica (Nogueira et al. 2006). Em áreas amazônicas, o GPR tem contribuído para a caracterização de depósitos neógenos, auxiliando no mapeamento de superfícies estratigráficas chaves da Formação Barreiras na Zona Bragantina, nordeste do Pará (Rossetti 2001, 2003), bem como de depósitos cretáceos da Formação Alter do Chão, no Estado do Amazonas (Silva 2005).

A aquisiçáo de dados de GPR no leste da ilha do Marajó foi facilitada pela topografia extremamente plana, o que permitiu a coleta de dados sem necessidade de correção topográfica. Os resultados aqui apresentados corroboram proposiçóes anteriores (e.g., Rossetti 2010) que ressaltam a importância de deformaçóes tectônicas no desenvolvimento da sedimentação miocênica e quaternária tardia da porção oriental da ilha do Marajó.

\section{CARACTERIZAÇÃO DA ÁREA DE ESTSUDO}

\section{Área de estudo e vias de acesso}

A ilha do Marajó se situa no nordeste do Estado do Pará, extremo norte do Brasil, estando a $87 \mathrm{~km}$ de Belém, entre os paralelos $0^{\circ}$ e $2^{\circ} \mathrm{S}$ e os meridianos $48^{\circ}$ e $51^{\circ} \mathrm{W}$ (Fig. 1). Essa área, de $49.606 \mathrm{~km}^{2}$, faz parte do complexo flúvio-marinho da foz do rio Amazonas. A ilha é limitada pelo rio Amazonas a norte, rios Pará e Tocantins a sul, e pelo Oceano Atlântico a leste. Entre a ilha e Belém se estende a baía do Marajó, com $18 \mathrm{~km}$ de largura, formada por uma mistura de água salgada do Atlântico e água doce dos rios Pará e Tocantins. 


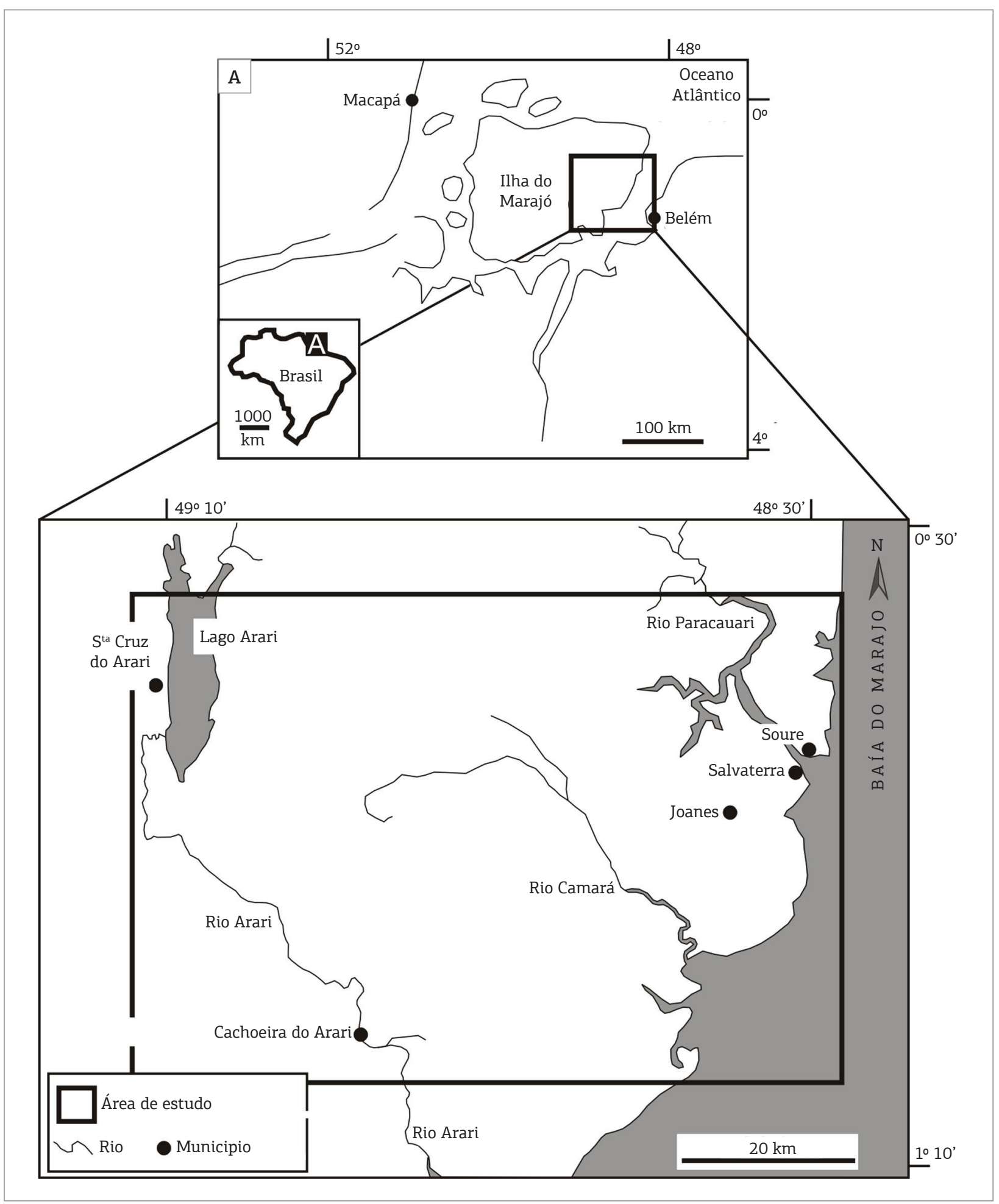

Figura 1. Localização da área de estudo na porção leste da ilha do Marajó.

A área de estudo compreende os municípios de Salvaterra, Cachoeira do Arari e Joanes. O acesso à área pode ser feito por via fluvial, seguindo pela baía do Marajó até o porto de Salvaterra e, a partir dali, por via terrestre em estrada pavimentada até a cidade homônima. O município de
Salvaterra tem quase $1.044 \mathrm{~km}^{2}$ e é margeado pelo rio Paracauari e pela baía do Guajará. É limitado pelos municípios de Soure, a norte, e Cachoeira do Arari, a sul. O município de Cachoeira do Arari ocupa uma área de $3.116 \mathrm{~km}^{2}$, sendo limitado a norte pelos municípios de Soure e Santa 
Cruz do Arari, a sul pela baía de Marajó e a leste pelo município de Salvaterra. A área de Joanes é limitada pelos municípios de Salvaterra e Soure a norte, pelo rio Camará a oeste e pela baía do Marajó a leste e sul (Fig. 1).

\section{Contexto geológico}

A ilha do Marajó se insere, em sua porção oeste, no Sistema de Graben do Marajó (SGM) e, em sua porção leste, na Plataforma do Pará (PP). O SGM, localizado na parte norte do Estado do Pará, possui forma alongada de direçáo NW-SE. Este graben apresenta feiçôes geológicas e geomorfológicas características à distensão mesozóica e à neotectônica pós-miocênica. A disposiçáo do depocentro do SGM e de suas falhas associadas sugere arquitetura em semi-graben, com formação de sub-bacias (Mexiana, Limoeiro, Cametá e Mocajuba) separadas por falhas direcionais ENE e NE-SW (Villegas 1994).

$\mathrm{O}$ arcabouço estratigráfico do SGM (Fig. 2) consiste em um pacote de rochas sedimentares formadas desde o Cretáceo inferior até o recente, atingindo espessuras na ordem de $11 \mathrm{~km}$. Em subsuperfície inclui sedimentos: clástico-arenosos da Formaçáo Breves (Albiano); clásticos conglomeráticos da Formação Jacarezinho (Aptiano-Cenomaniano); sílticos e argilosos da Formação Anajás (Eocretáceo); areníticos friáveis, finos a grossos, com frequentes níveis conglomeráticos e intercalaçóes de argilitos da Formação Limoeiro (Cretáceo Superior); carbonático-siliciclásticos da Formação Marajó

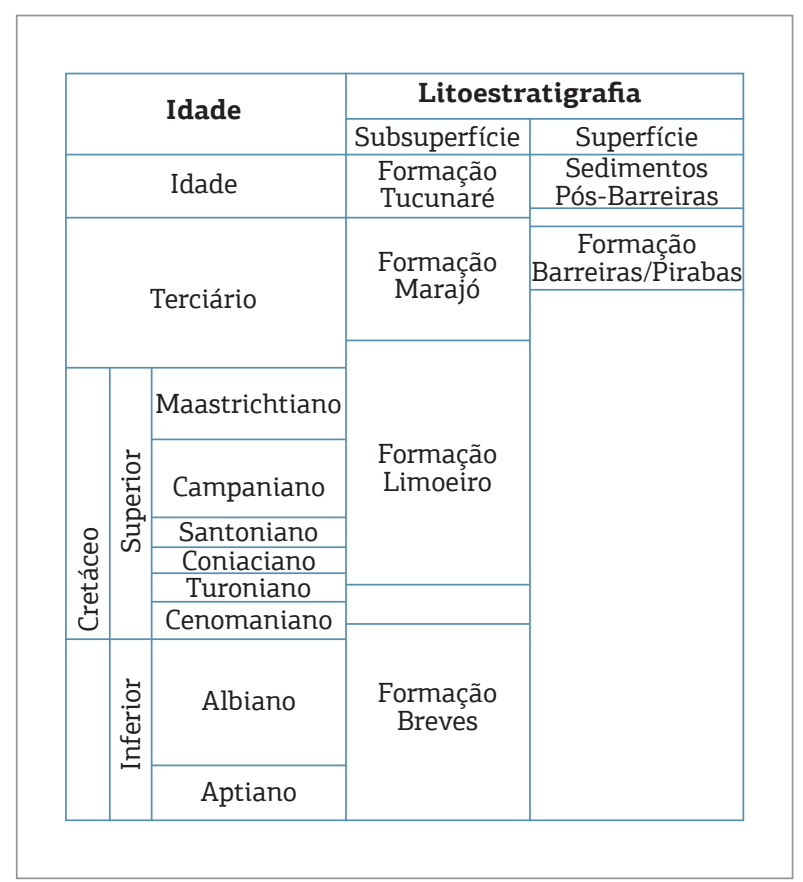

Figura 2. Síntese da estratigrafia do Sistema de Graben do Marajó (modificada de Rossetti \& Valeriano 2007).
(Paleoceno-Eoceno); e areníticos quartzosos intercalados a argilitos da Formação Tucunaré (Quaternário). Estas unidades são atribuídas a ambientes que variam de fluvial a marinho raso e aluvial (Avenius 1988, Villegas 1994).

A porção leste da ilha do Marajó está inserida na PP, que corresponde a uma extensa área tectonicamente estável entre as bacias paleozóicas do Amazonas e do Parnaíba, cujos limites são os arcos de Gurupá e Tocantins. Essa plataforma apresenta pequenas fossas com profundidades na ordem de 3.500 m (Rezende \& Ferradaes 1971). Uma dessas depressóes, sobre a qual se posiciona o lago Arari, dominante na paisagem no leste da ilha, é de direção norte-sul e se estende para norte, onde se conecta com a Sub-bacia de Mexiana (Azevedo 1991). Em superfície, esta porção da ilha é composta por depósitos miocênicos (sucessão Pirabas/Barreiras), além de depósitos denominados de sedimentos pós-barreiras (Pleistoceno TardioHoloceno). A Formação Pirabas consiste em uma sucessão de fácies carbonáticas com intercalações de folhelhos e arenitos, atribuídos a ambiente marinho raso plataformal restrito, bem como lagunas e mangues conectados a ambiente estuarino (Góes et al. 1990). A Formação Barreiras é constituída de arenitos maciços a estratificados, argilitos laminados a maciços e pelitos com acamamentos heterolíticos, cuja origem é atribuída a ambiente estuarino (Rossetti $\&$ Truckenbrodt 1989, Rossetti 2001). Os sedimentos pós-barreiras englobam arenitos finos a médios, maciços e de coloração amarelada, atribuídos a processos gravitacionais e eólicos (Rossetti \& Truckenbrodt 1989) (Fig. 2).

\section{MATERIAIS E MÉTODOS}

Esse trabalho foi baseado na análise de um total de $16 \mathrm{~km}$ de seçôes lineares de dados de GPR adquiridos na ilha do Marajó, PA (Fig. 3). A aquisição dos dados foi feita utilizando o sistema de GPR SYR-2 da Geophysical Survey Systems Inc. O método GPR é de fácil utilização e se baseia na emissão e registro de ondas eletromagnéticas de alta frequência (normalmente de 10 a $2000 \mathrm{MHz}$ ) que sofrem reflexão nas interfaces e estruturas geológicas rasas (inferiores a $50 \mathrm{~m}$ ).

Neste trabalho foram empregadas antenas blindadas de $200 \mathrm{MHz}$. A escolha de antenas dessa frequência baseou-se na facilidade de operação e bom desempenho em terrenos da Região Bragantina, nordeste do Estado do Pará (Rossetti et al. 2001, Rossetti 2003), que possuem depósitos com características litológicas similares aos desta área de estudo.

As seçóes foram adquiridas em modo contínuo, velocidade de caminhamento constante e posicionamento feito 


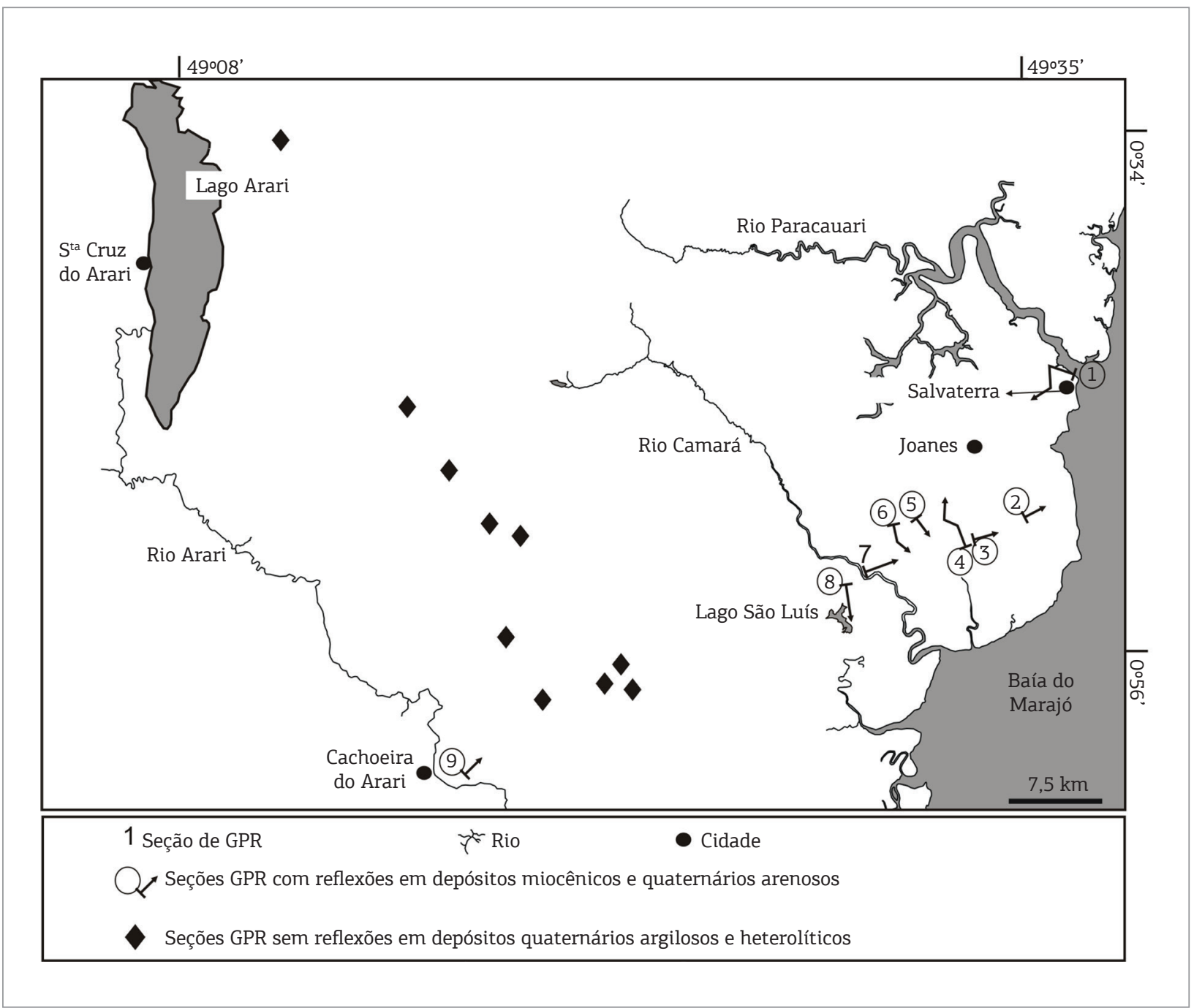

Figura 3. Localização das seções de GPR adquiridas no leste da ilha do Marajó. Setas indicam sentido de aquisição de dados.

por meio de marcos com espaçamento variando de 10 a 100 m. Durante a aquisição foi empregada janela de aquisição de 150 e 180 ns. O processamento das seçóes foi feito com o aplicativo Radan for Windows. Foram utilizados filtros e ganhos para melhorar a resolução e amenizar ruídos, a fim de proporcionar melhor visualização das reflexóes e possibilitar a interpretação mais precisa do arcabouço tectono-estratigráfico da área de estudo.

Após processamento, as seções de radar serviram de base para o traçado de superfícies estratigráficas e a interpretação dos padrôes de reflexôes ("fácies de radar"). As seções foram interpretadas tomando por base parâmetros relativos à configuração e geometria das reflexóes (e.g., Payton 1977). As seçôes de radar foram analisadas de forma bidimensional, proporcionando caracterização da geometria e heterogeneidade litológica, o que contribuiu para o reconhecimento, descrição e interpretação das unidades sedimentares.

\section{SEDIMENTOLOGIA E ESTRATIGRAFIA}

A Formação Barreiras aflora em várias pequenas exposiçōes na porção leste da ilha do Marajó, onde consiste principalmente em arenitos e argilitos maciços, fortemente intemperizados, além de conglomerados. Estas litologias, que mostram cores variando de branco, amarelo, lilás a vermelho, são localmente endurecidas devido à forte cimentação por óxidos e hidróxidos de ferro. As melhores exposiçóes dessa unidade foram registradas ao longo de falésias costeiras nas adjacências da cidade de Salvaterra (Figs. 1 e 4A a 4D). Como verificado em outras áreas dos Estados do Pará e Maranhão (e.g., Rossetti, 2004), o topo da Formaçáo Barreiras na área de estudo é sistematicamente marcado por discordância com relevo erosional de vários metros em escala de afloramento. Essa discordância é, ainda, marcada por colunas verticais 
de concreçôes ferruginosas relacionadas ao paleossolo laterítico de expressão regional. Por vezes, o paleossolo in situ é ausente, sendo substituído por depósitos residuais de laterita e seixos de quartzo. Para oeste das falésias costeiras, a Formação Barreiras está exposta ao longo de poucos cortes de estradas e pequenas pedreiras, onde concreçóes lateríticas e/ou depósitos residuais de clastos lateríticos e seixos de quartzo estão presentes (Figs. 4E a 4G).
Onde exposta, a Formação Barreiras é sobreposta por areias quartzosas de granulometria fina, seleção moderada a alta, com pequenos fragmentos dispersos de carvão, que fazem parte dos sedimentos pós-barreiras (Figs. 4A a 4G). Esses depósitos, que alcançam até $3 \mathrm{~m}$ de espessura, foram datados por luminescência opticamente estimulada em grãos de quartzo e exibiram idades do Pleistoceno Tardio ao Holoceno (Tatumi et al. 2008). Testemunhos de sondagem

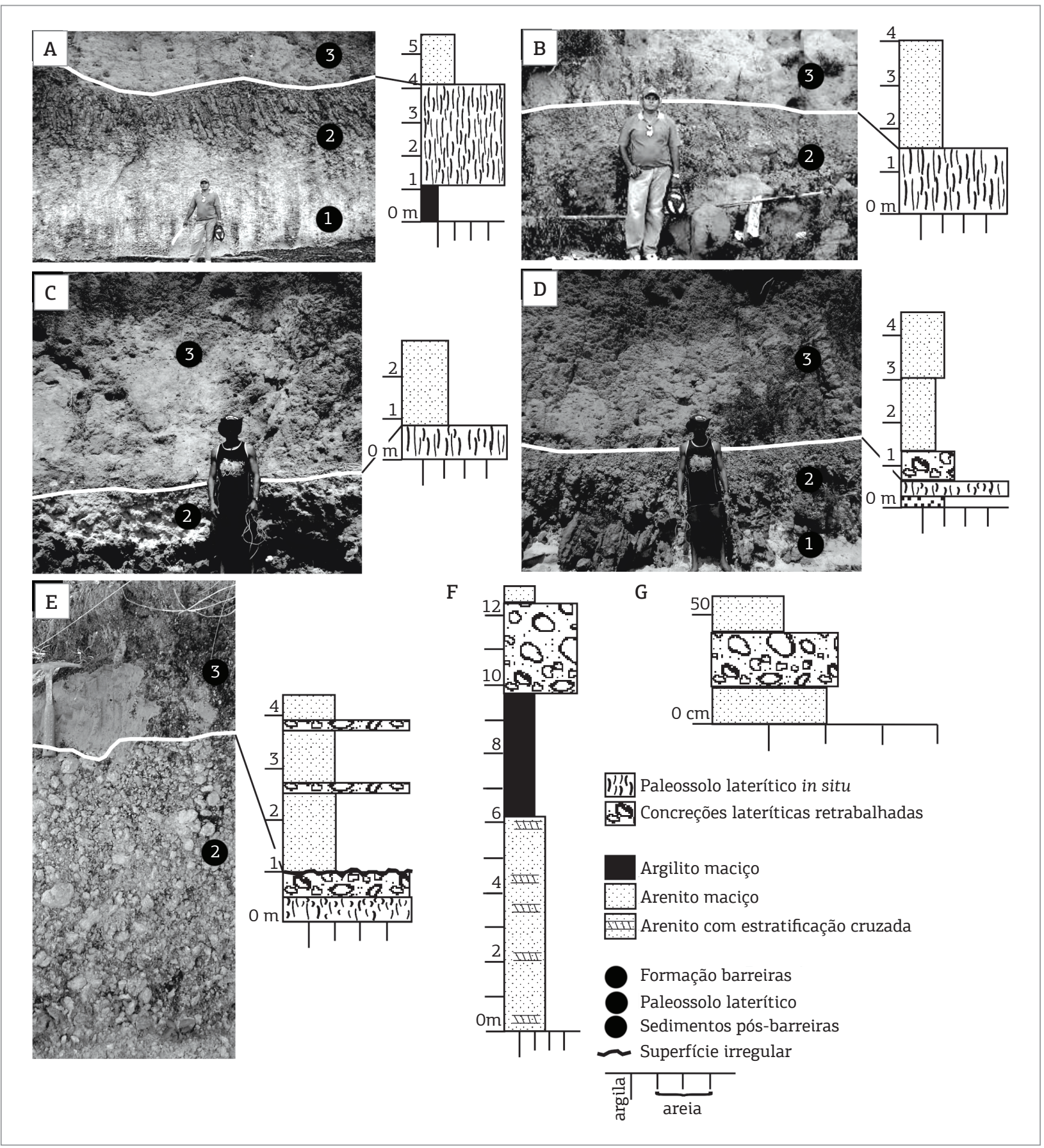

Figura 4. Exposições da Formação Barreiras em falésia costeira na cidade de Salvaterra (A-D), em corte de estrada $(E, G)$ e em trincheira na porção sudeste dessa cidade (F) (martelo $=35 \mathrm{~cm}$ de comprimento). 
adquiridos a oeste da área onde ocorrem as exposiçóes da Formação Barreiras indicaram espessuras mais significativas dos sedimentos pós-barreiras, registrados até a profundidade de $120 \mathrm{~m}$ na margem oeste do lago Arari (Miranda et al. 2009, Castro et al. 2010, Rossetti 2010). Estes autores descrevem depósitos heterolíticos, arenosos e argilosos, localmente ricos em matéria orgânica vegetal, com idades radiogênicas variando entre $55.082( \pm 12.354)$ e $3.184( \pm 37)$ ${ }^{14} \mathrm{C}$ anos A.P. É importante destacar que náo houve registro da Formação Barreiras sob os depósitos quaternários em nenhum dos poços estudados por esses autores.

\section{UNIDADES DE RADAR}

A interpretação litológica, estratigráfica e estrutural dos conjuntos de seçôes de radar só foi possível pelo conhecimento geológico prévio da área. Ressalta-se que neste trabalho são apresentados somente os conjuntos de seçóes que melhor caracterizaram a geologia da região e as feiçôes estruturais de interesse para este estudo. Além das informaçôes geológicas anteriormente mencionadas, foram verificados vários locais onde o horizonte laterítico do topo da Formação Barreiras ocorre apenas 1 ou $2 \mathrm{~m}$ abaixo da superfície. Com base nessas informaçôes, foi possível relacionar as reflexôes contínuas e de alta frequência do topo da unidade A, descrita a seguir, com a discordância com paleossolo laterítico do topo da Formação Barreiras (ver também o item discussóes). Esses dados foram fundamentais para o entendimento do significado geológico das reflexóes, permitindo analisar a continuidade dos estratos em subsuperfície rasa e, com isto, auxiliar na caracterização das estruturas tectônicas.

De modo geral, as seçôes de radar registraram os depósitos sedimentares de interesse até profundidades estimadas entre 10 e 15 m, considerando constantes dielétricas médias para o meio variando entre 3 e 5 . Essas estimativas de profundidade foram confirmadas nas falésias, onde os estratos sedimentares são expostos. O resultado revelou concordância dos valores estimados com as profundidades reais de marcos estratigráficos de fácil correlaçáo nas seçôes de radar. Tendo em vista este fato, as seçôes de radar são apresentadas com os valores em tempo e profundidade, considerando constante dielétrica igual a 3 para o meio investigado.

Para fins descritivos, as reflexôes registradas são enquadradas em nove categorias de acordo com sua configuração e geometria, que foram designadas: caótica, divergente, paralela a subparalela, ondulante, hiperbólica, em canal, em mound, sem reflexóes, e superfície estratigráfica (Fig. 5). Uma parte das seçóes amostradas foi adquirida entre os lagos São Luís e Arari (losangos na Fig. 3). Em nenhuma das seçóes geradas nesse setor foi possível a discriminação de padróes ou unidades internas (Fig. 6). Portanto, elas não estão incluídas na descrição de unidades de radar apresentadas. A outra parte das seçôes (i.e., seçôes 1 a 8) foi adquirida entre o lago São Luís e a costa leste da ilha, sendo uma (i.e., seção 9) obtida imediatamente a leste da cidade de Cachoeira do Arari (Fig. 3). A distribuição e o padrão dessas reflexóes levaram ao reconhecimento de duas unidades de radar principais, i.e., unidades A e B, descritas na sequência deste trabalho e ilustradas nas Figs. 7 a 10.

\section{Unidade A}

A unidade $A$, que ocorre na base das seçóes de radar, mostra espessuras variando entre 6 e $12 \mathrm{~m}$. A base desta unidade não foi registrada dentro da janela de aquisição empregada. Seu topo é tipicamente irregular, sendo marcado por reflexóes de grande amplitude, que se destacam fortemente em todas as seçóes de radar, podendo ser acompanhada por outras reflexôes de configuração hiperbólica. As reflexôes de alta amplitude se caracterizam, ainda, por truncarem reflexóes subjacentes e apresentarem reflexóes sobrepostas que terminam em onlap ou downlap, o que define a superfície estratigráfica chave atribuída à parada de sedimentação e/ou erosão. É interessante notar que, além de reflexôes hiperbólicas, esta superfície é, com frequência, sobreposta por intervalos de alguns metros, onde dominam reflexóes caóticas, ou seja, caracterizadas por segmentos descontínuos e de disposição aleatória, que mostram amplitude e continuidade lateral baixas. Geograficamente, reflexóes do tipo superfície estratigráfica mostram relevo, em geral, irregular, sendo caracterizadas por segmentos interrompidos e deslocados verticalmente, formando gradientes de até $7 \mathrm{~m}$. Segmentos deslocados são lateralmente limitados por áreas delgadas que formam alinhamentos verticais ou subverticais onde não ocorrem reflexôes ou as reflexôes são caóticas. Esses alinhamentos se projetam para cima, afetando os refletores fortes do topo da unidade A, bem como reflexôes da unidade B sobrejacente. Localmente, ocorrem sucessóes de segmentos inclinados dessa superfície, de distribuição escalonada, e dispostos de forma progressivamente mais rebaixada em uma dada direção (ver retângulo branco no centro da Fig. 8A). Além disso, conjuntos de falhas são arranjadas de forma a configurar conjugados que lembram estruturas “em flor" (e.g., ver retângulo na Fig. 7C).

Internamente à unidade $\mathrm{A}$, verificam-se reflexôes com configuraçôes e geometrias diversas. Assim, além de reflexôes caóticas, ocorrem proporções variadas de reflexôes dos tipos paralela a subparalela, côncava, e divergente (ver Fig. 5 para visualização desses tipos de reflexóes). Reflexóes paralelas a subparalelas correspondem a uma série de reflexóes concordantes, de alta amplitude e continuidade lateral moderada a alta, dispostas horizontalmente, formando conjuntos tabulares 

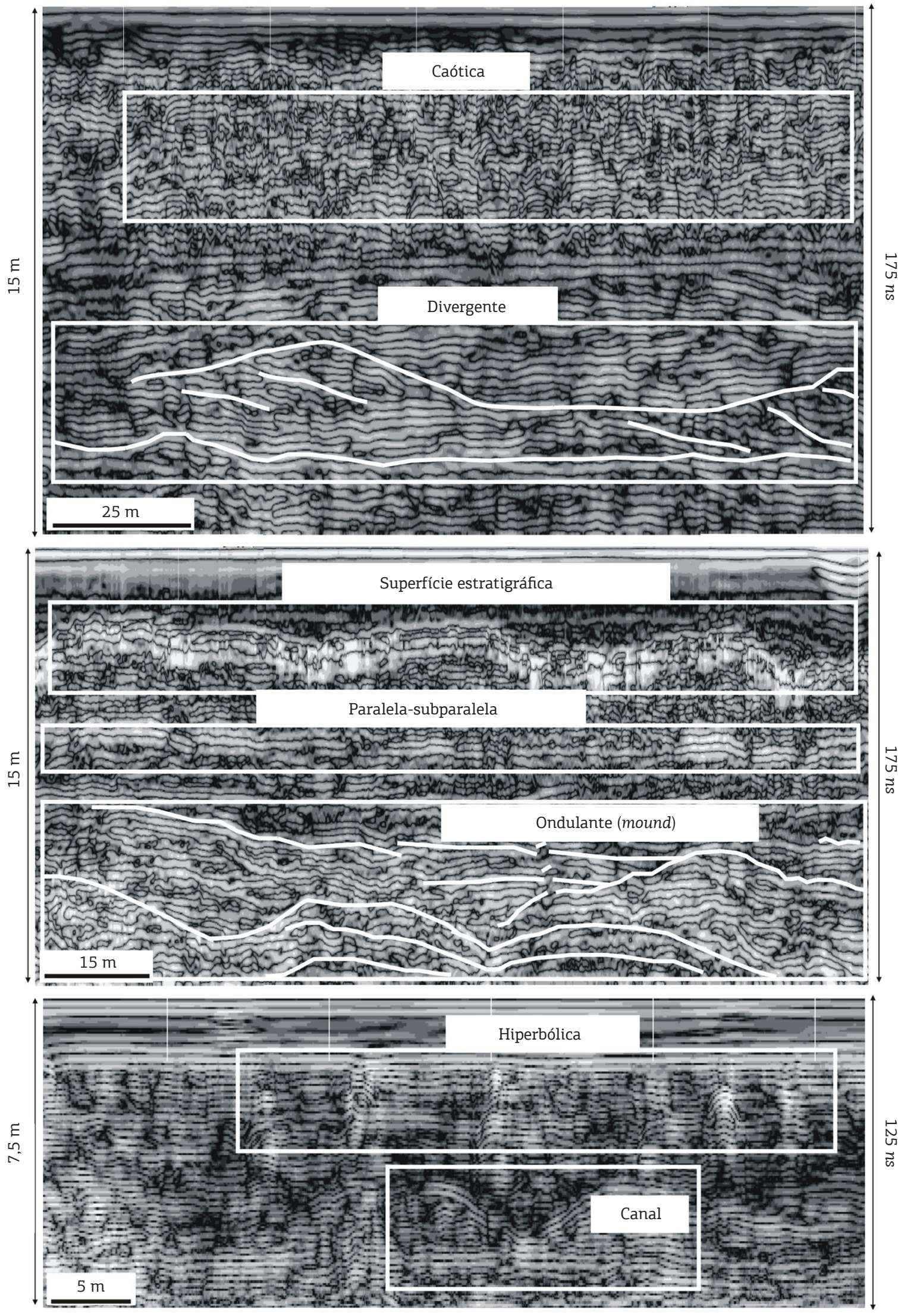

Figura 5. Tipos de padrão de reflexões reconhecidos nas seções de radar de penetração no solo (GPR) estudadas. 

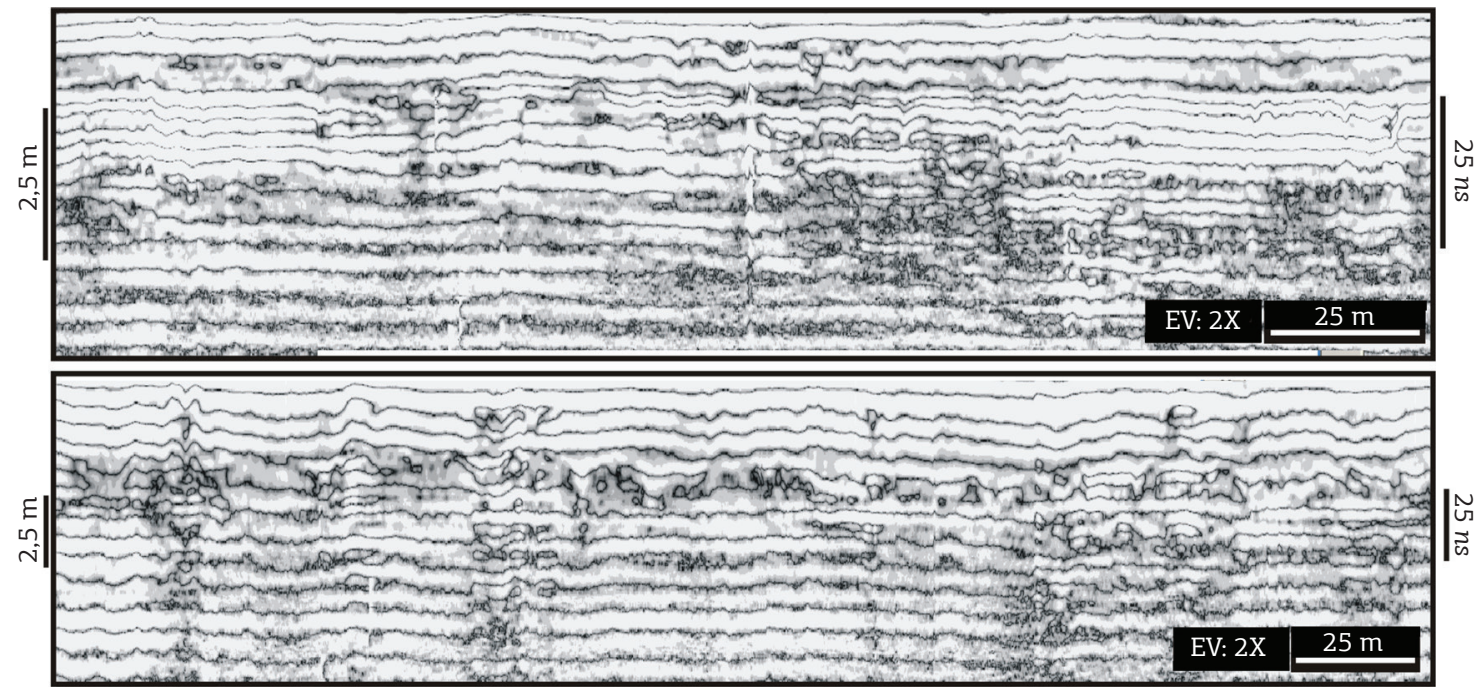

Figura 6. Exemplo de seções de radar adquiridas entre os lagos São Luís e Arari (ver localização na Fig. 3), representativas da sedimentação quaternária (ver localização na Fig. 3). Notar a ausência de sinal de radar nessas seções, relacionadas ao predomínio de litologias argilosos e à presença de água conata de natureza salina e/ou salobra.

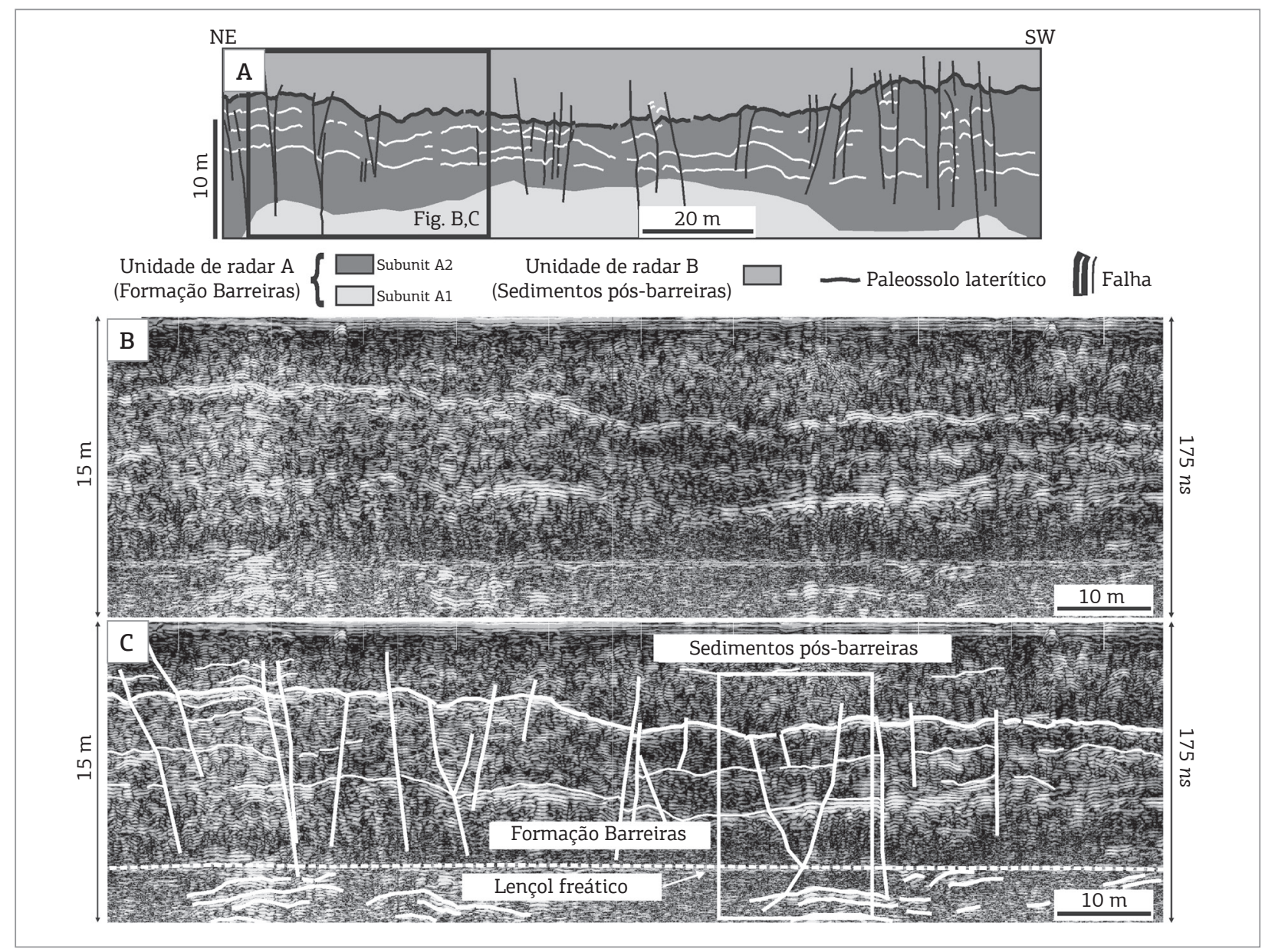

Figura 7. Seção de radar 1 (ver localização na Fig. 3). (A) Seção geológica interpretada a partir dos dados de radar (modificada de Rossetti et al. 2012). (B-C) Exemplo de imagem de radar ilustrando detalhes das reflexões, com suas respectivas interpretações estratigráficas e estruturais. Notar em $C$ a presença de falhas subverticais que afunilam para baixo, configurando estrutura do tipo "em flor" (retângulo). 

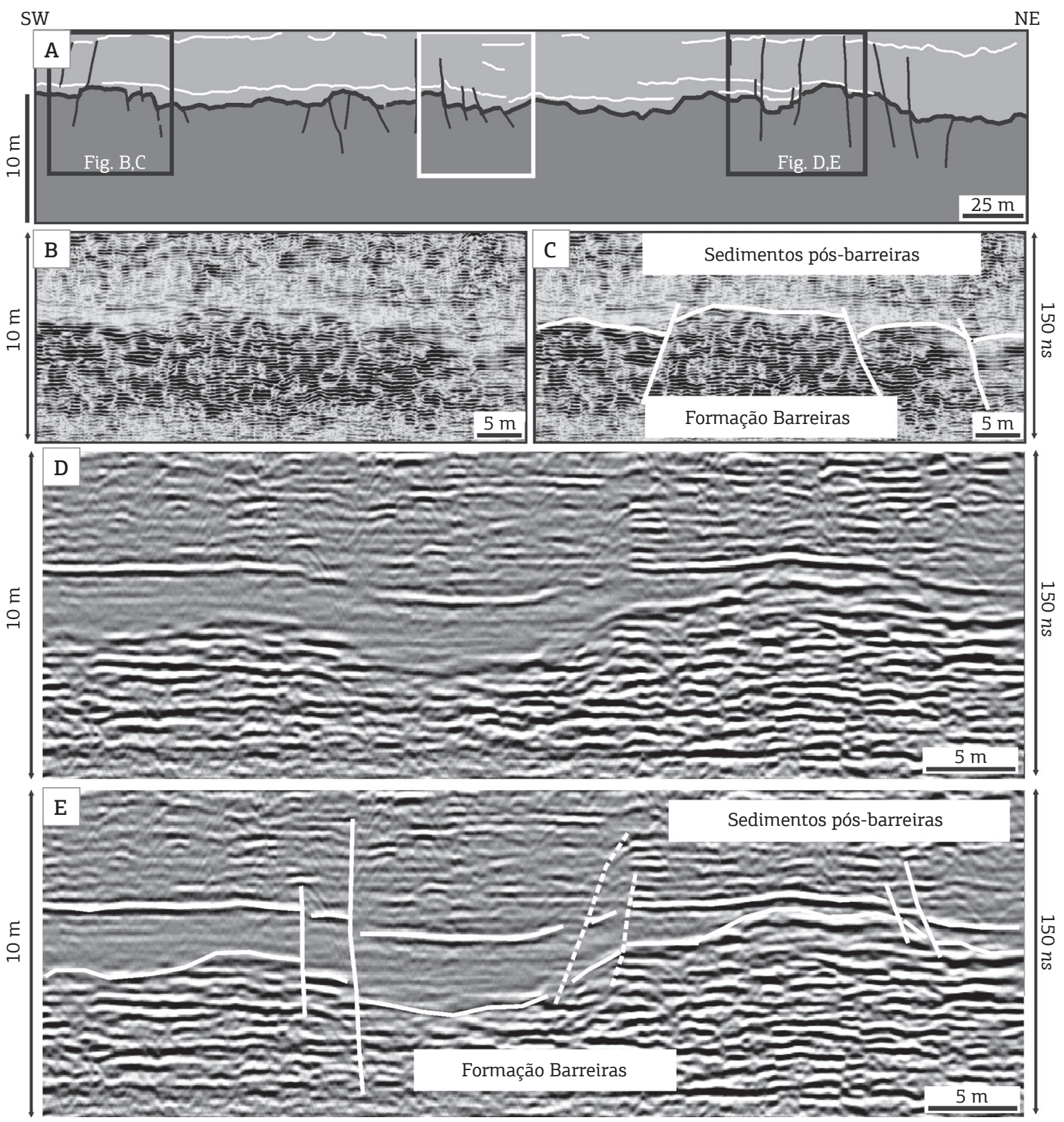

Figura 8. Seção de radar 2 (ver localização na Fig. 3 e legenda na Fig. 7). (A) Seção geológica interpretada a partir dos dados de radar (ver legenda na Fig. 7). Notar a presença de falhas escalonadas em padrão dominó (retângulo branco central). (B-E) Exemplos de imagens de radar ilustrando detalhes das reflexões, com suas respectivas interpretações estratigráficas e estruturais. Notar, ainda, em D e E falhas subverticais que se prolongam para cima, interceptando a discordância e afetando os estratos quaternários sobrejacentes.

suavemente ondulantes. Reflexões côncavas ocorrem em áreas localizadas das seções, em geral se estendendo lateralmente por alguns metros ou dezenas de metros. Essas reflexóes, de amplitude moderada, formam concavidades que interceptam bruscamente reflexôes sobrejacentes e são sobrepostas por reflexôes concordantes ou discordantes com as reflexóes que definem este padrão. Reflexôes divergentes formam conjuntos localizados de reflexôes inclinadas (ângulos $<30^{\circ}$ ), que são interceptadas bruscamente por outras reflexôes sobrejacentes e terminam em onlap ou downlap contra reflexóes subjacentes. Lateralmente, essas reflexóes divergentes intergradam com as demais reflexôes já descritas.

Além das reflexões previamente referidas, que formam conjuntos definidos por outras reflexôes de disposição em geral 

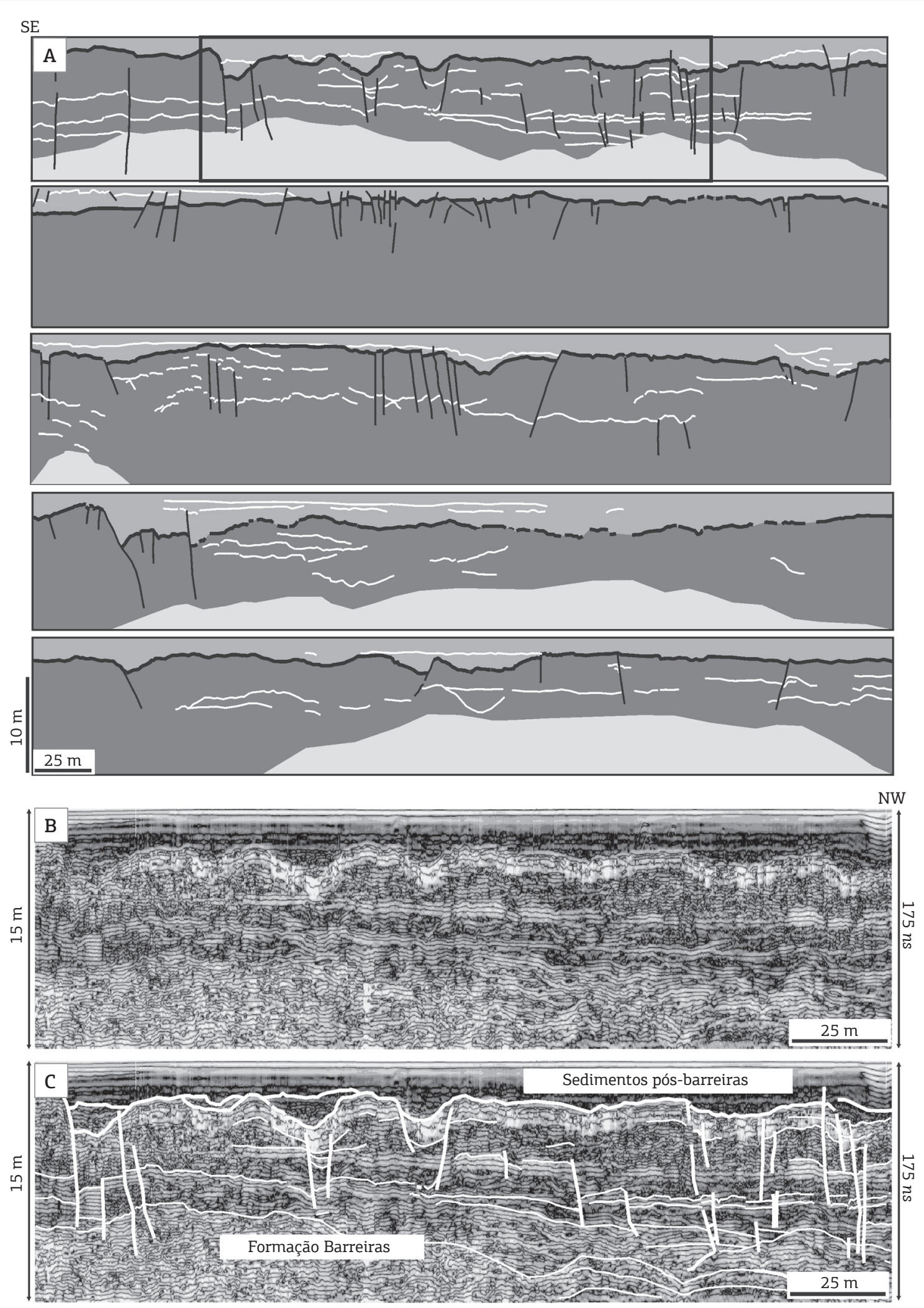

Figura 9. Seção de radar 4 (ver localização na Fig. 3 e legenda na Fig. 7). (A) Seção geológica interpretada a partir dos dados de radar. (B-C) Exemplo de imagem de radar ilustrando detalhes das reflexões, com suas respectivas interpretações estratigráficas e estruturais. Notar em B e C a forte ondulação das reflexões na base da Formação Barreiras e várias falhas subverticais que afetam principalmente os estratos sobrepostos, também dessa mesma unidade. 
planar, a base da unidade A em várias das seçôes estudadas contém conjuntos de reflexôes fortemente ondulantes que caracterizam pacotes com geometria em mound. Estas podem ser internamente compostas por conjuntos de reflexôes alternadamente côncavas e convexas. Lateralmente, estes conjuntos, aqui designados de subunidade A1 para diferenciar dos intervalos de reflexôes sobrejacentes referidos de subunidade A2, podem desaparecer de maneira abrupta. A subunidade A1 (e.g., Figs. 10A a 10G) ocorre em profundidades estimadas variáveis, em geral abaixo de $6 \mathrm{~m}$. Pacotes com reflexóes ondulantes são delimitados, em seu topo, por reflexóes de alta amplitude e de continuidade lateral moderada. Os conjuntos
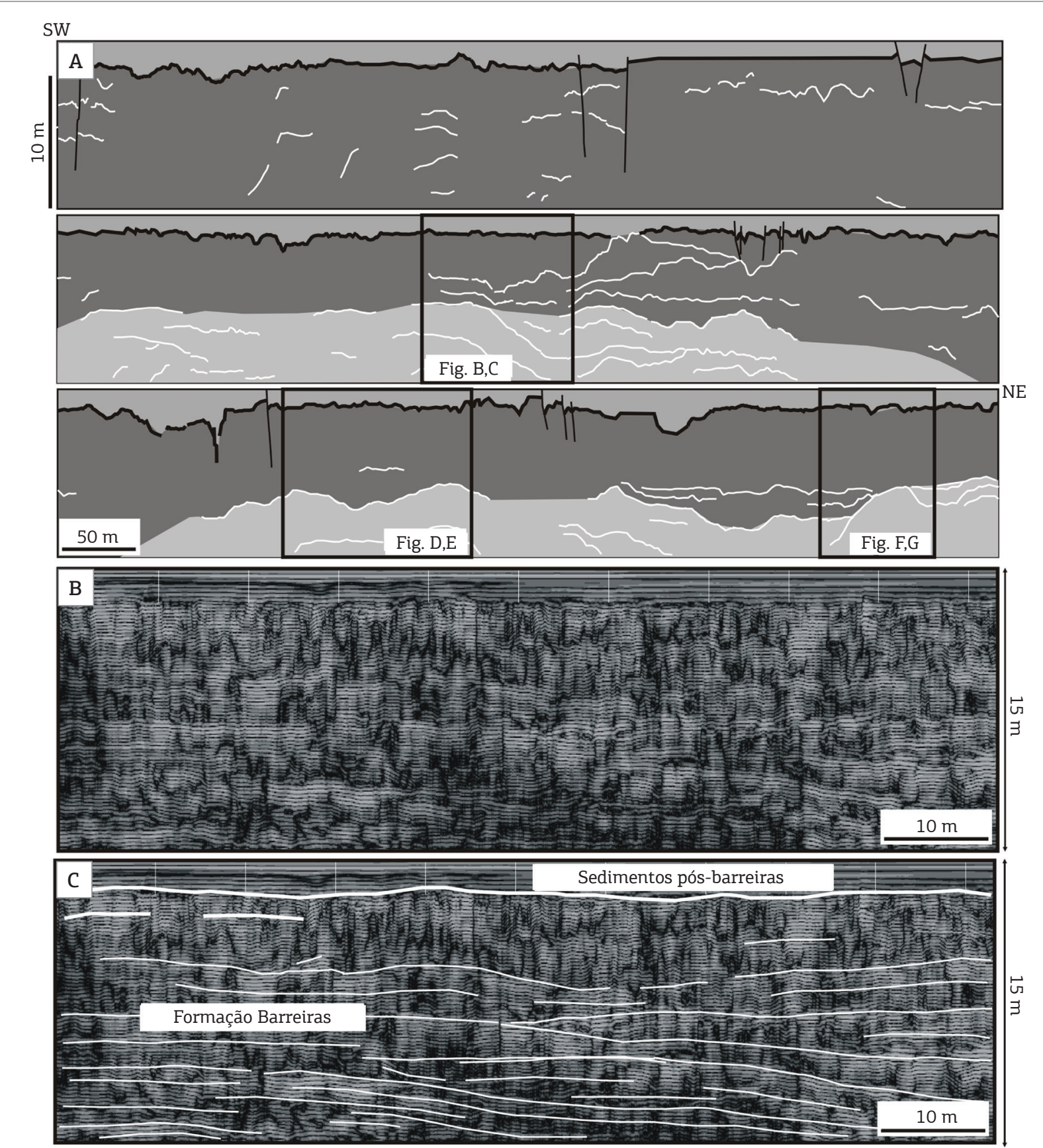

Figura 10. Seção de radar 7 (ver localização na Fig. 3 e legenda na Fig. 7). (A) Seção geológica interpretada a partir dos dados de radar (ver legenda na Fig. 7). (B-G) Exemplos de imagens de radar ilustrando detalhes das reflexões, com suas respectivas interpretações estratigráficas e estruturais. Notar nos detalhes das Figs. B a G a forte ondulação das reflexões na metade inferior da Formação Barreiras e o onlap/downlap das reflexões sobrejacentes sobre elas. Observar que a metade superior dessa unidade não foi afetada pelo dobramento. 

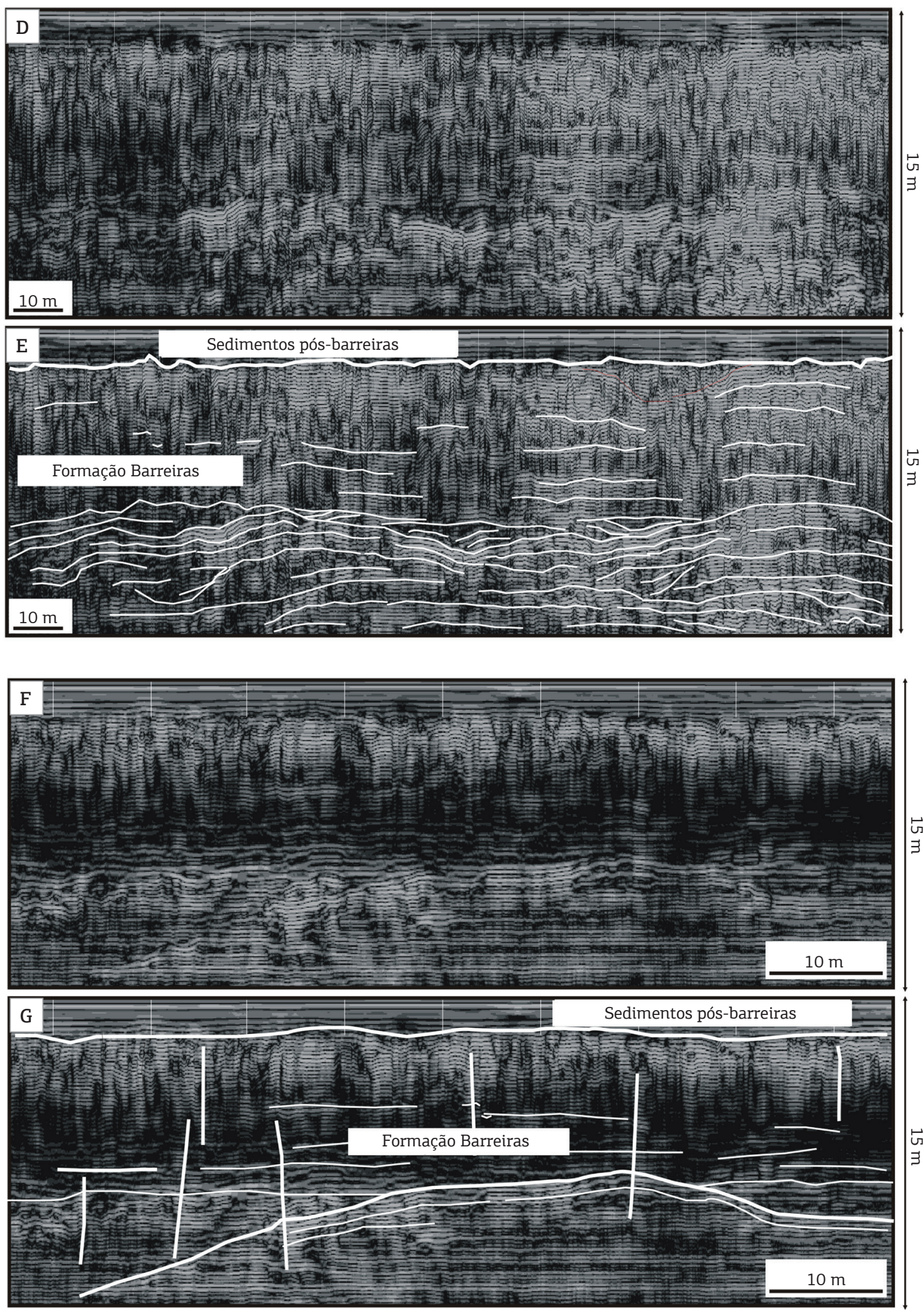

Figura 10. Continuação. 
de reflexôes ondulantes são salientados nas seções de GPR por estarem em descontinuidade com reflexóes sobrejacentes, geralmente com terminaçôes em onlap contra sua superfície de topo. A não observação desse pacote de reflexóes ondulantes na base da Unidade A se deve a sua ausência ou à falta de sinal de radar, já que a base das seçóes referentes a esta unidade está próxima do limite de profundidade.

\section{Unidade B}

A unidade $\mathrm{B}$, que ocorre sistematicamente sobreposta à unidade A em todas as seçóes estudadas, possui espessuras estimadas entre 1 e $10 \mathrm{~m}$. Embora a distribuição de espessuras desta unidade seja variável na área de estudo, nota-se que os menores valores estão concentrados nas seçôes localizadas entre o lago São Luís e a margem leste da ilha.

A unidade $B$ se destaca da unidade subjacente não só pela presença de marco estratigráfico indicado pelas reflexóes de altas amplitudes já descritas anteriormente, mas também por apresentar internamente conjuntos de reflexóes com configuraçóes bem definidas, em geral dos tipos subparalelas e, mais raramente, paralelas. Ocasionalmente, essas reflexóes são interceptadas por reflexôes côncavas de baixa amplitude, que se estendem lateralmente por várias dezenas de metros. Reflexôes caóticas ocorrem localmente, embora em pequena proporção relativamente às demais reflexôes.

Próximas da base, as reflexóes que compóem a unidade B são de amplitude baixa, o que resulta em grande contraste com as reflexóes de alta amplitude do topo da unidade A. Além disto, é importante salientar que essas reflexôes de topo são sobrepostas por reflexóes da unidade A que, com frequência terminam em onlap e downlap contra as reflexóes subjacentes.

\section{DISCUSSÃO}

Os resultados apresentados neste trabalho para a porção leste da ilha do Marajó sugerem, em seu conjunto, evoluçáo sedimentar neógena e quaternária sob influência tectônica. Informaçôes disponíveis na literatura consistindo na análise de anomalias de drenagem, lineamentos morfoestruturais e paleodrenagem com base em dados orbitais, já haviam sugerido controle tectônico na ilha (Mantelli \& Rossetti 2009, Souza \& Rossetti 2011). Esses dados podem ser aqui aproveitados para reforçar a presença de estruturas reconhecidas nas seçôes de radar. Além disso, informaçôes de subsuperfície foram cruciais na confirmação da influência de estruturas tectônicas no desenvolvimento de estratos miocênicos e pós-miocênicos do leste da ilha, além de ter servido, por vezes, para comprovar a ligaçáo entre estruturas mapeadas em superfície com as detectadas em subsuperfície.
Um elemento de significado primordial para a interpretação das seçôes de GPR foi o amplo reconhecimento de refletores de alta amplitude, correlacionados por várias dezenas de quilômetros, que definem um marco estratigráfico chave. Essas características, aliadas ao fato dos refletores truncarem reflexóes subjacentes e apresentarem relação de downlap e onlap com as reflexóes sobrejacentes, permitem sua atribuição a uma superfície de descontinuidade estratigráfica regional de natureza erosiva. Tendo em vista as informaçôes geológicas da área de estudo, o mais provável é que esta superfície corresponda à discordância marcada por paleossolo laterítico do topo da Formação Barreiras. Essa interpretação é feita com base na ocorrência desses refletores a poucos metros da superfície em vários locais, onde se pode observar, em afloramento, a discordância do topo da Formação Barreiras (Fig. 4, ver também descrição anterior do item Sedimentologia e Estratigrafia). É interessante observar, ainda, que refletores fortes com características similares foram previamente detectados em seçóes GPR adquiridas no topo de falésias, onde essa discordância associa-se com paleossolo laterítico em outras áreas de ocorrência da Formação Barreiras (e.g., Rossetti et al. 2001, Rossetti 2004).

As reflexóes hiperbólicas localmente associadas à superfície estratigráfica já referida são condizentes com a presença de superfície irregular comumente associada às discordâncias. Em tais circunstâncias, ocorrem reflexôes que assumem a forma de hipérboles à medida que a antena se afasta da área causadora deste efeito (Van Heteren et al. 1998). As reflexôes caóticas, observadas logo abaixo dos refletores relacionados à discordância, são compatíveis com a interpretação sugerida, já que uma das principais características da pedogênese é a homogeneização dos estratos. Outros tipos de reflexôes prevalecem subjacentes ao horizonte com influência pedogenética, que são condizentes com sedimentos estratificados. Isto é sugerido, por exemplo, pela presença de reflexóes paralelas a subparalelas, divergentes e côncavas, relacionadas com estratos horizontais, estratos cruzados e depósitos em canal, respectivamente. A boa visualização destas reflexôes na unidade A sugere abundância de litologias arenosas, já que pacotes argilosos têm a tendência de atenuar o sinal eletromagnético (Van Heteren et al. 1998, Ellefsen 1999). Esta interpretação litológica, aliada às características da superfície estratigráfica acima interpretada, é compatível com o relacionamento da unidade A com a Formação Barreiras, já que esta unidade contém elevado volume de arenitos maciços e estratificados, e abundantes feiçôes de canal (e.g., Rossetti $\&$ Truckenbrodt 1989).

Baseando-se nos dados geológicos disponíveis na região, e considerando a associação da unidade A com a Formaçáo Barreiras, os depósitos que ocorrem sobre a discordância são atribuídos aos sedimentos pós-barreiras. Afloramentos 
da Formação Barreiras em vários locais do nordeste dos Estados do Pará e Maranhão, bem como ao longo da costa nordeste brasileira, são sobrepostos por estratos quaternários tardios, referenciados genericamente de sedimentos pós-barreiras (e.g., Rossetti \& Truckenbrodt 1989, Rossetti 2004, Rossetti 2010, Rossetti et al. 2011a,b). Estudos cronológicos enfocando estratos sobrejacentes à Formaçáo Barreiras na ilha do Marajó e na Zona Bragantina revelaram somente idades quaternárias tardias (Tatumi et al. 2008). A presença de reflexóes bem definidas nos depósitos correlacionados aos sedimentos pós-barreiras também sugere abundância de sedimentos arenosos, o que é condizente com o conteúdo litológico descrito para essa unidade.

O sinal homogêneo das reflexóes nas seçóes de radar que se estendem do lago São Luís ao lago Arari, formando padrão contínuo e horizontal (Fig. 6), deve ser interpretado com cautela. Dados derivados de testemunhos de sondagem nessa área sugerem domínio de estratos quaternários tardios em subsuperfície rasa (Miranda et al. 2009, Castro et al. 2010, Rossetti 2010). Contrariamente aos demais sedimentos pós-barreiras que se sobrepóem à Formação Barreiras na porção oriental da área de estudo, esses estratos são dominados por litologias argilosas e heterolíticas que contêm, esporadicamente, corpos arenosos delgados com volumes variáveis de água salobra ou salgada (Gonzalez 1984, Kobayashi 1979). Estas se constituem em características desfavoráveis à propagação de ondas de GPR (e.g., Van Heteren et al. 1998). Então, é possível que os sinais homogêneos das seçóes adquiridas nesses depósitos reflitam esta condição de subsuperfície. A ausência de sinal de radar nesse caso é de interesse, podendo ser usada como característica da sedimentaçáo quaternária que ocorre entre os lagos São Luís e Arari. Essa característica advém do predomínio de litologias argilosas e heterolíticas, aliadas ao conteúdo de água conata salobra e salgada. A hipótese mais lógica para explicar esta condição é que o espessamento de estratos quaternários entre os lagos São Luís e Arari se deve ao aumento da taxa de sedimentação neste setor da ilha, o que é decorrente da criação de espaço acomodacional provavelmente por subsidência tectônica. A não detecção da Formação Barreiras nessa área e o rápido desaparecimento do horizonte altamente resistivo relacionado à discordância do topo dessa unidade, que por vezes coincide com a presença de lineamentos morfoestruturais, reforça esta proposição. Sugere-se, portanto, que neste setor da ilha, a Formação Barreiras sofreu deslocamento de, pelo menos, vários metros, proporcionando a criação de novo espaço para acomodar sucessão mais expressiva e litologicamente mais variável dos sedimentos pós-barreiras, do que a verificada na porção oriental da área de estudo. Como sugerido em trabalhos prévios, a retomada da sedimentação quaternária na ilha ocorreu após longo tempo de estabilidade tectônica que se sucedeu à deposição da Formação Barreiras no Mioceno (Rossetti 2004, Rossetti \& Valeriano 2007).

De grande interesse para reforçar a hipótese tectônica acima proposta é a análise da natureza irregular das reflexóes relacionadas à discordância do topo da Formação Barreiras. Em parte, isto se deve à própria característica erosiva desta superfície, formada por exposição subaérea e desenvolvimento de solo durante período prolongado de não deposição associado à queda do nível do mar no Tortoniano (Rossetti 2006). Entretanto, o fato dessa superfície indicar deslocamentos localmente exagerados leva à formulação da hipótese de origem não associada somente a processos erosivos. Locais onde essa discordância é representada por segmentos de reflexôes bruscamente interrompidos e deslocados sugerem movimentação vertical dos estratos. Reflexôes subjacentes a esses segmentos e concordantes com os deslocamentos condizem com tal interpretação. Esse fato, associado à presença de áreas delgadas com ausência de reflexóes ou com reflexóes caóticas, onde ocorre interrupçáo brusca e deslocamento vertical dos segmentos de reflexóes, é condizente com a ocorrência de falhas. Muitos trabalhos têm interpretado planos de falha em seçóes GPR por meio de refletores interrompidos seguindo esse mesmo padrão (e.g., Meschede et al. 1997, Van Heteren et al. 1998, Basson et al. 2002, Rashed et al. 2003, Ferry et al. 2004, Patidar et al. 2008).

A presença de segmentos de reflexôes escalonados é condizente com sucessóes de falhas com deslocamento por gravidade. Além disso, conjuntos de falhas arranjadas de forma a configurar conjugados que lembram estruturas "em flor", como observado nas seçóes estudadas, sugerem deformação sob regime de transcorrência. Estudos prévios já haviam sugerido essas estruturas na ilha do Marajó (e.g., Barbosa Filho et al. 1989, Travassos \& Barbosa Filho 1990). Adicionalmente, estudos anteriores já haviam detectado falhas em seções de GPR adquiridas na Formação Barreiras e nos sedimentos pós-barreiras da Zona Bragantina, nordeste do Pará (e.g., Rossetti et al. 2001, Rossetti 2004). Vários estudos recentes também vêm registrando falhas em depósitos correlatos também no nordeste do Brasil (e.g., Saadi \& Torquato 1992, Bezerra \& Vita-Finzi 2000, Bezerra et al. 2005, Furrier et al. 2006, Bezerra et al. 2008, Nogueira et al. 2010, Rossetti 2010). O fato da unidade A apresentar maior volume de segmentos deslocados verticalmente leva a interpretar que esta unidade foi mais fortemente deformada do que a unidade $B$.

Outra feição observada nas seções GPR que merece ser destacada são as reflexôes fortemente ondulantes, com geometria em mound ou convexas para cima, que ocorrem em associaçáo à subunidade A1. O fato dessa subunidade ser lateralmente descontínua e desaparecer bruscamente, ser sobreposta por reflexóes que terminam contra ela em onlap, 
e ser delimitada no topo por reflexôes de alta amplitude, sugere que este conjunto de estratos pode se constituir em uma unidade estratigráfica à parte, seja inserida na Formação Barreiras, seja mais antiga.

Embora a possibilidade da subunidade A1 ser mais antiga não possa ser totalmente descartada com base no estudo presente, é interessante lembrar que trabalhos anteriores subdividiram a Formação Barreiras em, pelo menos, três unidades estratigráficas, formadas por flutuaçôes de alta frequência do nível do mar relativo (Rossetti 2001). Neste trabalho, realizado na Sub-bacia de Cametá, porção sudoeste do Sistema de Graben do Marajó, a autora descreveu falhas e dobras, que foram relacionadas à deformação sinsedimentar associada à reativação de falhas. Trabalho recente realizado no litoral do Estado da Paraíba também registra falhas e dobras na Formação Barreiras (e.g., Rossetti et al. 2011a). Levando em consideração esses artigos, é possível relacionar as reflexôes ondulantes detectadas na base da unidade A com estratos dobrados. Seçóes de radar que registram a Formaçáo Barreiras no litoral paraense já haviam detectado este mesmo padrão de reflexóes ondulantes (Rossetti 2004). Embora até o momento não existam evidências de campo que comprovem deformação por compressão afetando estratos da Formaçáo Barreiras, o modelo tectônico (Costa et al. 1996) prevê este tipo de deformação em associação às zonas de transcorrência para o litoral paraense. Adicionalmente, a compressão associada às zonas de transcorrência tem sido sugerida para justificar dobras da Formação Barreiras no nordeste do Brasil (Bezerra et al. 2008).

Considerando os dados acima apresentados, levanta-se a hipótese de que as reflexóes ondulantes da subunidade A1 correspondam a estratos dobrados, formando sinclinais e anticlinais. O mais provável é que essa deformação dúctil tenha ocorrido sindeposicionalmente, tendo afetado somente uma parte da Formação Barreiras, correspondente à porção basal das seçôes GPR. Esta deformação não teria atuado nos estratos sobrejacentes, depositados posteriormente ao evento deformacional, pois esses não foram dobrados. Entretanto, a associação dessas possíveis dobras com falhas, algumas inclusive com prolongamento para cima na seção quaternária, atesta recorrências de esforços deformacionais com o tempo.

\section{CONCLUSÕES}

O GPR constitui uma excelente ferramenta de investigação indireta objetivando o registro de estruturas tectônicas em subsuperfície rasa do leste da ilha do Marajó. As seções adquiridas são de boa qualidade e permitiram analisar os estratos sedimentares em detalhe, o que possibilitou detectar deslocamentos frequentes das reflexóes, por vezes significativos, que só podem ser explicados por deslocamentos tectônicos. A geometria das falhas sugere deslocamentos normais e transcorrentes. Embora a maioria das falhas tenha afetado principalmente a seção miocênica, várias delas se prolongam para cima, afetando também a sedimentação quaternária, o que permite inferir a recorrência de deformaçáo distensiva em tempos relativamente jovens. Além disso, as bases de muitas seçôes mostram padrão de reflexôes ondulantes, que sugere sinclinais e anticlinais resultantes de deformação por compressão, possivelmente ainda durante a deposição da Formação Barreiras. A distribuição geográfica das seçóes GPR sugere que a regiáo compreendida entre os lagos Sáo Luís e Arari sofreu maior subsidência, onde foi criado espaço para acomodar volume mais expressivo de sedimentos argilosos e heterolíticos quaternários tardios. A ocorrência associada de falhas e dobras nos estratos miocênicos e de falhas nos sedimentos quaternários reflete, muito provavelmente, reativaçôes de deformaçôes transcorrentes ligadas aos sistemas riftes da margem equatorial brasileira. Os bons resultados alcançados com GPR na ilha do Marajó levam a propor a continuidade deste tipo de estudo para melhorar a reconstituição de sua história tectono-sedimentar em tempo miocênicos e quaternários.

\section{AGRADECIMENTOS}

Este trabalho foi financiado pela Fundação de Amparo à Pesquisa do Estado de São Paulo - FAPESP (Projeto\#004/15518-6). Os agradecimentos são extensivos ao Museu Paraense Emílio Goeldi (MPEG), por ceder o equipamento GPR SYR-2 da Geophysical Survey Systems Inc utilizado na coleta dos dados geofísicos. 


\section{REFERÊNCIAS}

Avenius C.G. 1988. Cronostratigraphic study of the post-rift/sin-rift unconformity, Marajó Rift system. Belém, Texaco/Canada Report, 6 p.

Azevedo R.P. 1991. Tectonic evolution of Brazilian equatorial continental margin basins. PhD Thesis, Royal School of Mines Imperial College, London, $412 \mathrm{p}$.

Barbosa Filho C.M, Teixeira L.B., Travassos W.A.S. 1989. Tectonismo terciário na área do Tapajós. In: Congresso Brasileiro de Geofísica, Rio de Janeiro, v. 3, p. 1252- 1259

Basson U., Ben-Avraham Z., Garfunkel Z., Lyakhovsky V. 2002. Development of recent faulting in the southern Dead Sea Rift according to GPR imaging. EGU Stephan Mueller Special Publication Series, 2:35-48

Bemerguy R.L. 1981. Estudo Sedimentológico dos Paleocanais da Região do Rio Paracauari, Ilha do Marajó, Estado do Pará. MS Dissertation, Universidade Federal do Pará, Belém, 95 p.

Bezerra F.H.R., Fonseca V.P., Vita-Finzi C., Lima-Filho F.P., Saadi A. 2005. Liquefaction-induced structures in Quaternary alluvial gravels and gravels sediments, NE Brazil. Engineering Geology, 76(3-4):191-208

Bezerra F.H.R., Neves B.B.B., Correa A.C.B., Barreto A.M.F., Suguio K. 2008. Late Pleistocene tectonic-geomorphological development within a passive margin - the Cariatá trough, northeastern Brazil. Geomorphology, 97:555-582

Bezerra F.H.R., Vita-Finzi C. 2000. How active is a passive margin? Paleoseismicity in northeastern Brazil. Geology, 28:591-594.

Borges W.R., Porsani J.L. 2002. Investigações geofísicas na borda da bacia sedimentar de São Paulo. Revista Brasileira de Geofísica. 20(3):187-192

Castro D.L., Carvalho A.M., Branco R.M.G.C. 2005. Uso do GRP no estudo da estruturação interna de depósitos de eolianitos na região costeira de Uruoca - CE. Revista de Geologia, 18:245-54.

Castro D.R., Rossetti D.F., Pessenda L.C. 2010. Facies, $\delta^{13} \mathrm{C}, \delta^{15} \mathrm{~N}$ and $\mathrm{C} / \mathrm{N}$ analyses in a late Quaternary compound estuarine fill, northern Brazil. Marine Geology, 274(1-4):135-150.

Cavalcanti G.M.L. 1979. Geofísica aplicada à prospecção de água subterrânea na área do Rio Paracauari, Ilha do Marajó, Pará. MS Dissertation, Universidade Federal do Pará, Belém, 88 p.

Ceia M.A.R., Carrasquilla A.A.G., Travassos J.M. 2004. Levantamento GPR em afloramentos turbidíticos da Bacia de Almada-BA. Revista Brasileira de Geociências, 34(3):411-418.

Chow J., Angelier J., Hua J.J., Lee J.C., Sun R. 2001. Paleoseismic event and active faulting: from ground penetrating radar and highresolution seismic reflection profile across the Chihshang Fault eastern Taiwan. Tectonophysics, 333(1-2):241-259.

Chowksey V., Joshi P., Maurya D.M., Chamyal L.S. 2011. Ground penetrating radar characterization of fault-generated Quaternary colluvio-fluvial deposits along the seismically active Kachchh Mainland Fault, Western India. Current Science, 100(6): 915-921.

Christie M., Tsoflias G.P., Stockli D.F., Black R. 2009. Assessing fault displacement and off-fault deformation in an extensional tectonic setting using 3-D ground-penetrating radar imaging. Journal of Applied Geophysics, 68(1):9-16

Costa J.B.S, Bemerguy R.L., Hasui, Y., Borges M.S.B., Ferreira Jr. C.R.P., Bezerra P.E.L., Costa M.L., Fernandes J.M.G. 1996. Neotectônica da Região Amazônica: aspectos tectônicos, geomorfológicos e deposicionais. Geonomos, 4(2):23-44.
Costa J.B.S, Hasui Y., Bermerguy R.L., Soares Jr. A.V., Villegas J.M.C. 2002. Tectonics and paleogeography of the Marajó Basin, northern Brazil. Anais da Academia Brasileira de Ciências, 74(3):519-531.

Dagallier G., Laitinen A.L., Malartre F., Campenhout I.P.A.M.V., Veeken P.C.H. 2000. Ground penetration radar application in a shallow marine Oxfordin limestone sequence located on the eastern flank of the Paris Basin, NE France. Sedimentary Geology, 130:149-165.

Dominic D.F., Egan K., Carney C., Wolfe P.J., Boardman M.R. 1995. Delineation of shallow stratigraphy using ground penetrating penetrating radar. Journal of Applied Geophysics, 33(1-3):167-175.

Dourado, João C., Filho W.M., Braga, A.C.O., Nava N. 2001. Detecção de cavidades em arenitos utilizando gravimetria, eletrorresistividade e GPR. Revista Brasileira de Geofísica, 19(1):19-32.

Ellefsen K.J. 1999. Effects of layered sediments on the guided wave in crosswell radar data. Geophysics, 64(6):1698-1707.

Ferry M., Meghraoui M., Girard J.F., Rockwell T.K., Kozaci O., Akyuz S., Barka A. 2004. Ground-penetrating radar investigations along the North Anatolian fault near Izmit, Turkey: constraints on the rightlateral movement and slip history. Geology, 321):85-88.

Furrier M., Araújo M.E., Meneses L.F., 2006. Geomorfologia e tectônica da Formação Barreiras no Estado da Paraíba. Geologia USP. Série Científica, 6(2):61-70.

Góes A.M., Rossetti D.F., Nogueira A.C.R., Toledo P.M. 1990. Modelo deposicional preliminar da Formação Pirabas no nordeste do Estado do Pará. Boletim do Museu Paraense Emílio Goeldi. Série Ciências da Terra, 2:3-15.

Gonzáles A.A.C. 1984. Estudo geofísico regional sobre água subterrânea da Ilha do Marajó, Pará, Brasil. MS Dissertation, Universidade Federal do Pará, Belém, 143 p.

Jol H.M., Smith D.G. 1991. Ground penetrating radar of northern lacustrine deltas: Canadian. Journal of Earth Sciences, 28(12):1939-1947.

Kobayashi C.N. 1979. Métodos geofísicos aplicados à prospecção de água subterrânea no Município de Ponta de Pedras, Ilha do Marajó, Pará. MS Dissertation, Universidade Federal do Pará, Belém, 93 p.

Lee K., Mcmechan G.A., Gani M.R., Bhattacharya J.P., Zeng X., Howell Jr. C.D. 2007. 3-D Architecture and sequence stratigraphic evolution of a forced regressive top truncated mixed-influenced delta, Cretaceous Wall Creek Sandstone, Wyoming, U.S.A. Journal of Sedimentary Research, 77(4):303-323.

Mantelli L.R., Rossetti D.F. 2009. Significado tectônico de lineamentos de drenagem no sudoeste da ilha do Marajó. Revista Brasileira de Geociências, 39(1):1-13.

Meschede M., Asprion U., Reicherter K. 1997. Visualisation of tectonic structures in shallow-depth high-resolution groundpenetrating radar (GPR) profiles. Terra Nova, 9(4):167-170

Miranda M.C.C., Rossetti D.F., Pessenda L.C.R. 2009. Quaternary paleoenvironments and relative sea-level changes in Marajó Island (Northern Brazil): facies $\delta 13 \mathrm{C}, \delta 15 \mathrm{~N}$ and $\mathrm{C} / \mathrm{N}$. Paleogeography, Paleoclimatology, Palaeoecology, 282(1-4):19-31.

Nogueira F.C.C., Bezerra F.H.R., Castro D.L., Branco R.M.G.C. 2006 Radar de Penetração no Solo (GPR) aplicado ao estudo de estruturas tectônicas neógenas na Bacia Potiguar, NE do Brasil. Revista de Geologia, 19(1):23-33

Nogueira F.C.C., Bezerra F.H.R., Fuck R.A. 2010. Quaternary fault kinematics and chronology in intraplate northeastern Brazil. Journal of Geodynamics, 49(2):79-91. 
Patidar A.K., Maurya D.M., Thakkar M.G., Chamyal L.S. 2008. Evidence of neotectonic reactivation of the Katrol Hill Fault during late Quaternary and its GPR characterization. Current Science, 94:338-346.

Payton C.E. 1977. Seismic stratigraphy - applications to hydrocarbon exploration. American Association of Petroleum Geologists Memoir, 26:516p

Pereira A.J, Gambôa L.A.P, Silva M.A.M., Rodrigues A.R, Costa A. 2003. A utilização do Ground Penetrating Radar (GPR) em estudos de estratigrafia na praia de Iataipuaçú, Maricá (RJ). Revista Brasileira de Geofísica, 21(2):163-172.

Porsani J.L. 1999. Ground Penetrating Radar (GPR): proposta metodológica de emprego em estudos geológicosgeotécnicos nas regiões de Rio Claro e Descalvado - SP. PhD Thesis, Universidade Estadual de São Paulo, Rio Claro, 145 p.

Rashed M., Kawamura D. Nemoto H. Miyata T. Nakagawa K. 2003. Ground penetrating radar investigations across the Uemachi fault, Osaka, Japan. Journal of Applied Geophysics, 53(2):63-75.

Rashed M., Nakagawa K., 2004. High-resolution shallow seismic and ground penetrating radar investigations revealing the evolution of the Uemachi Fault System, Osaka, Japan. The Island Arc, 13(1):144-156.

Reicherter K.R., Reiss S. 2011. The Carboneras Fault Zone (southeastern Spain) revisited with Ground Penetrating Radar Quaternary structural styles from high-resolution images. Geologie en Mijnbouw, 80(3-4):129-138.

Rezende W., Ferradaes J. 1971. Integração geológica regional da bacia sedimentar da Foz do Amazonas. Belém. Petrobras. Departamento de Exploração. Relatório Interno, 27 p.

Rossetti D.F. 2001. Late Cenozoic sedimentary evolution in northeastern Pará, Brazil, within the context of sea level changes. Journal of South American Earth Sciences, 14(1):77-89.

Rossetti D.F. 2003. Delineating shallow Neogene deformation structures in northeastern Pará State using ground penetrating radar. Anais da Academia Brasileira de Ciências, 75(2):235-248.

Rossetti D.F. 2004. Paleosurfaces from northeastern Amazonia as a key for reconstructing paleolandscapes and understanding weathering products. Sedimentary Geology, 169(3-4):151-174.

Rossetti D.F. 2006. Evolução sedimentar miocênica nos Estados do Pará e Maranhão. Geologia USP. Série Científica, 6(2):7-18.Rossetti D.F. 2010. Tectonic control on the stratigraphy framework of Late Pleistocene and Holocene deposits in Marajó Island, State of Pará, eastern Amazonia. Anais da Academia Brasileira de Ciências, 82(2):439-450.

Rossetti D.F., Góes A.M., Valeriano M.M., Miranda M.C.C. 2008a. Quaternary tectonics in a passive margin: Marajó Island, Northern Brazil. Journal of Quaternary Science, 23:121-35.
Rossetti D.F., Valeriano M.M., Góes A.M., Thalles M. 2008b. Paleodrainage in Marajó Island (Northern Brazil) and its relation to Holocene relative sea-level. The Holocene, 18:923-34.

Rossetti D.F., Bezerra F.H.R., Góes A.M, Neves B.B.B. 2011a. Sediment deformation in Miocene and post-Miocene strata, Northeastern Brazil: evidence for paleoseismicity in a passive margin. Sedimentary Geology, 235(3-4):172-187.

Rossetti D.F., Bezerra F.H., Góes A.M., Valeriano M.M., Andrades-Filho C.O., Mittani J.C.R., Tatumi S.H., Brito-Neves B.B. 2011b. Late Quaternary sedimentation in the Paraiba Basin, Northeastern Brazil: landform, sea level and tectonics in Eastern South America passive margin. Palaeogeography, Palaeoclimatology, Palaeoecology, 300(1-4):191-204.

Rossetti D.F., Góes A.M., Souza L.S.B. 2001. Estratigrafia da Sucessão Sedimentar Pós-Barreiras (Zona Bragantina, Pará) com base em Radar de Penetração no Solo. Revista Brasileira de Geofísica, 19(2):113-130.

Rossetti D.F., Truckenbrodt W. 1989. Estudo paleoambiental e estratigráfico dos Sedimentos Barreiras e Pós-Barreiras na região Bragantina, nordeste do Pará. Boletim do Museu Paraense Emílio Goeldi. Série Ciências da Terra, 1(1):25-74.

Rossetti D.F., Valeriano M.M. 2007. Evolution of the lowest amazon basin modeled from the integration of geological and SRTM topographic data. Catena, 70:253-265.

Saadi A., Torquato J.R. 1992. Contribuição à Neotectônica do Estado do Ceará. Revista de Geologia da Universidade Federal do Ceará, 5:5-38.

Silva C.L. 2005. Análise da tectônica cenozóica da região de Manaus e adjacências. PhD Thesis, Universidade Estadual de São Paulo, Rio Claro, $306 \mathrm{p}$.

Souza L.S.B., Rossetti D.F. 2011. Caracterização de drenagem na porção leste da Ilha do Marajó e implicações tectônicas. Revista Brasileira de Geomorfologia, 12(1):69-83.

Tatumi S.H., Silva L.P., Pires E.L., Rossetti D.F., Góes A.M., Munita C.S. 2008. Datação de Sedimentos Pós-Barreiras no norte do Brasil: implicações paleogeográficas. Revista Brasileira de Geociências, 38(3):514-524.

Travassos W.A., Barbosa Filho C.M. 1990. Tectonismo terciário na área do Rio Tapajós, Bacia do Amazonas. Boletim de Geociências da Petrobrás, 4(3):299-314.

Van Heteren S., Fitzgerald D.M., Mckinlay P.A., Buynevich I.V. 1998. Radar facies of paraglacial barrier systems: coastal New England, USA. Sedimentology, 45(1):181-200.

Villegas J.M. 1994. Geologia estrutural da Bacia de Marajó. Belém (PA). MS Dissertation, Universidade Federal do Pará, Belém, 119 p.

Arquivo digital disponível on-line no site www.sbgeo.org.br 